\title{
Cuidar dos outros, cuidar de Deus - o testemunho de Etty Hillesum
}

\author{
Taking care of others, taking care of God - the \\ testimony of Etty Hillesum
}

MARIA LUÍSA RIBEIRO FERREIRA (ida

\section{Resumo}

O texto incide sobre o pensamento de Etty Hillesum enquanto representativa das éticas do cuidado mostrando o modo muito próprio como o viveu, quer na sua relação com os outros, quer na sua relação com Deus. Há uma breve apresentação do conceito de cuidado, considerando-o como uma dimensão identificadora do humano, seguem-se algumas reflexões sobre as éticas do cuidado, integrando-as no feminismo cultural e demarcando-as das éticas generalistas. Centrando-nos nos escritos ettianos - cartas e diários - apresentamos Hillesum enquanto judia holandesa, analisando o modo como viveu e morreu sob a ocupação nazi na segunda guerra mundial. Considerando-a como cuidadora por excelência, nela destacamos diferentes vertentes. É objectivo deste texto acompanhar a evolução de Etty, desde uma primeira fase, essencialmente terapêutica, até à vivência de uma plenitude espiritual em que se propõe ajudar os outros, inclusivamente o próprio Deus, do qual assume a fragilidade.

Palavras-chave: Cuidado. Éticas do cuidado. Feminismo cultural. O valor da oração. Fragilidade de Deus.

\footnotetext{
a Universidade de Lisboa, Lisboa, Portugal. Doutor em Filosofia, e-mail: luisarife@sapo.pt 


\section{Abstract}

The paper focuses on Etty Hillesum as representative of the ethics of care, showing the original way she chose to live, either caring of her friends, either caring of others, either caring of God himself. After presenting the concept of care, stressing his importance in the definition of human nature, we present the ethics of care as an expressive issue of cultural feminism, in contrast with global ethics. Using Hillesum's letters and diaries, we present her as a Jewish Dutch who lived and died under Nazi's occupation during the Second World War. With this text we aim to follow Etty's evolution - from therapeutic care to helping other people in stressing situations and ending to help God Himself, assuming His fragility.

Keywords: Care. Ethics of care. Cultural feminism. The importance of praying. the fragility of God.

\section{Introdução}

O presente estudo tem como finalidade essencial mostrar a originalidade e a evolução do pensamento de Etty Hillesum, integrando-a na linha das Éticas do Cuidado e usando para tal as suas Cartas (HILLESUM, 2008)e os seus Diários (HILLESUM, 2009). O texto estrutura-se em cinco tópicos de

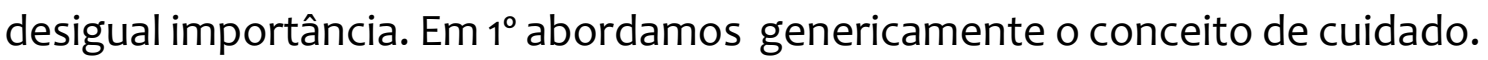
Começando pela análise etimológica do termo, e seguidamente o colocamos num registo antropológico e metafísico. A esta apresentação seguem-se considerações sobre a necessidade de cuidar das coisas e dos outros, em ordem a uma plena realização. Em $2^{\circ}$ mostramos que é pelo cuidado que nos identificamos e construímos como seres humanos, nas relações que estabelecemos com os outros. A compaixão, a solicitude, a responsabilidade e o amor são atitudes que ultrapassam um mecanismo meramente biológico e que nos abrem os caminhos da solidariedade e da comunhão social. Em $3^{\circ}$ contrastamos "dois modos de ser no mundo" - pelo trabalho e pelo cuidado. O ponto 4 toma o exemplo de Etty Hillesum enquanto cuidadora por excelência. Hillesum é apresentada, em primeiro lugar, na sua relação com Julius Spier, com quem estabeleceu uma relação esteita, inicialmente como discípula e depois como amante. Neste tópico acompanhamos o percurso espiritual de Etty, no qual teve um peso determinante a sua experiência no campo de Westerbork, onde os judeus eram retidos antes do serem enviados para Auschwitz. Em $5^{\circ}$ relatamos a conversão espiritual de Etty que no meio da 
provação mantém firme e fortalece a sua confiança em Deus, um Deus cuja fragilidade assume e a quem se propõe ajudar.

\section{O que entender por cuidar}

[...] cuidar é mais do que um acto, é uma atitude. Portanto abrange mais do que um momento de atenção, de zelo e de desvelo. Representa uma atitude de ocupação, de preocupação, de responsabilidade e de envolvimento afectivo com o outro (BOFF, 1999, p. 33).

Numa primeira acepção cuidar (do latim cuidare) é "curar”, "preocuparse com", "olhar por". No passado também se utilizava o verbo cuidar com o sentido de amar ou gostar de. Cuidar exige atenção ao outro e remete para a responsabilidade. No plano pessoal a responsabilidade refere-se aos actos pelos quais cada um terá de prestar contas. Mas no plano inter-subjectivo a responsabilidade tem a ver com a nossa relação com os outros, encarando-os zelosamente porque nos sentimos comprometidos com eles.

Hoje o termo cuidado abarca um conjunto de atitudes e assume uma diversidade de significados, todos eles relacionais, implica uma pluralidade de participantes que estabelecem, entre si, elos de protecção, de vigilância e de amor. Ao cuidar dos outros sentimo-nos responsáveis por eles, os incluímos na teia de ligações afectivas que constituem o nosso mundo, deixamos de nos pensar como referência determinante do mesmo. Mas cuidare também se liga a cogitare e a colere: no primeiro caso é um pensar activo, interessado e preocupado; no segundo um cultivar, proteger e tomar conta. Cuidamos de nós, cuidamos dos outros, cuidamos da terra e do mundo, ou seja, rompemos as fronteiras de um eu egoísta e atendemos à nossa circunstância. Etty Hillesum estendeu o seu cuidado ao próprio Deus.

Ultrapassando a etimologia e colocando-nos num registo antropológico e metafísico, verificamos que no cuidado há um descentramento do eu pela construção de uma relação personalizada, que se estabelece com algo ou com alguém, diferente de nós. Quando cuidamos interessamo-nos pelo outro e o tratamos como um fim em si mesmo. O cuidado mostra que somos uns com os outros e uns para os outros. Manifesta e concretiza a inclinação que sentimos 
perante pessoas e coisas. Implica um dinamismo e uma inquietude que reorienta a nossa atenção para além de nós mesmos.

O tema do cuidado está presente de diferentes modos, nas diferentes religiões. Pode-se vê-lo nos personagens centrais do relato bíblico do Paraíso - Adão deverá cuidar do jardim em que foi colocado. Saltando séculos, verificamos que uma preocupação dominante do Papa Francisco é o cuidado da terra, a nossa casa comum. Esta é a temática central da Encíclica Laudato Si', (FRANCISCO, 2015) um documento determinante para quem pretenda viver uma ecologia integral. E na sequência deste texto, complementando-o na atenção aos múltiplos seres que habitam a terra, o cuidado também surge na Encíclica Fratelli Tutti, como apelo à descentração e ao respeito pela diferença (FRANCISCO, 2020).

\section{O cuidado como dimensão identificadora do humano}

A necessidade de cuidado faz-se sentir logo que nascemos. Nenhum humano consegue sobreviver sem que dele se ocupem. O que, para além dos cuidados básicos de alimentação, higiene e acompanhamento, exige a presença dos afectos, pois a privação de relações afectivas marca-nos tanto como a fome ou a incultura. Cuidar prende-se com as emoções, com a empatia, a simpatia e a generosidade, instaura uma gramática de mimetismo pela qual nos tornamos solidários, desprendidos dos nossos interesses e mais próximos dos outros. Ao cuidar deles construímos pontes e desenhamos um terreno de partilha, no qual nos reconhecemos e gratificamos.

No seu livro Aprender a rezar na era da técnica, Gonçalo M. Tavares (TAVARES, 2007) traça-nos o retrato terrífico de um personagem, Lenz Buchmann, um homem totalmente destituído do sentimento de cuidado. Este pode ser percebido quando recusa um gesto mínimo de solidariedade que lhe é solicitado por uma doente moribunda - deitar no correio uma carta para o seu filho. E justifica esta atitude alegando que ela ultrapassa o seu estatuto de médico:

[...] aquela carta não era de facto o seu mundo, não era da sua física, da sua ciência, não pertencia ao mundo das suas máquinas de efeitos espantosos [...] 
não pertencia sequer ao mundo mais orgulhoso dos animais, ao mundo dos cavalos fortes (TAVARES, 2007, p. 75).

Lenz abomina e despreza as pessoas possuidoras daquilo a que chama "um coração mole", cujos actos constituem uma ameaça para a manutenção da cidade. Combate a compaixão que classifica como "uma espécie de proteína da fraternidade", muito do agrado dos filósofos da Igreja. Buchmann pertence ao reino de quem ataca os fracos e humildes, despreza as pessoas pela fragilidade que revelam. No seu intuito de defender uma raça de sobrehumanos à qual pensa pertencer, acaba por morrer como pária, abandonado por todos, confinado ao isolamento, privado da sua humanidade. De facto, esta não se define apenas pela razão, pois um robô consegue raciocinar melhor e mais depressa do que um humano. Mas uma máquina é destituída de compaixão, de solicitude, de responsabilidade e de amor, ou seja das exigências presentes na atitude de quem cuida. E igualmente determinantes nas chamadas éticas do cuidado.

\section{Breves reflexões sobre as éticas do cuidado}

Entre as taxonomias que procuram classificar a diversidade de éticas contemporâneas, salientamos as "éticas do cuidado" como um conjunto de orientações que se debruçam sobre o modo como nos relacionamos uns com os outros e com a Natureza. E mais uma vez lembramos Leonardo Boff, no contraste por ele estabelecido entre o cuidado e o trabalho - dois modos de habitar o mundo:

O modo de ser-no-mundo pelo trabalho dá-se na forma de inter-acção e de intervenção. O ser humano [...] pelo trabalho constrói o seu "habitat", adapta o meio ao seu desejo e conforma o seu desejo ao meio. Diferente é o modo de ser em que domina o cuidado pois [...] este não se opõe ao trabalho mas confereIhe um tonalidade diferente. Pelo cuidado não vemos a natureza e tudo o que nela existe como objectos [...]. Experimentamos os seres como sujeitos, como valores, como símbolos que remetem a uma Realidade fontal (BOFF, 1999, p. 95).

As éticas que valorizam o cuidado, preferindo-o aos valores da justiça ou do dever, conferem uma especial importância ao relacionamento pessoal, à convivialidade e aos afectos, apostando na partilha, na compaixão e na 
solidariedade. Esta deverá estender-se às diferentes culturas, às diferentes pessoas, aos diferentes seres - humanos e não humanos, vivos e não vivos.

As éticas do cuidado têm sido valorizadas por algumas correntes feministas que combatem as éticas generalistas, essencialmente ligadas ao conceito de justiça e de dever. O chamado "feminismo cultural" releva os aspectos positivos dessa mundividência, procurando com eles transformar $\mathrm{o}$ mundo em que vivemos. Nas diferentes linhas em que se concretiza, notamos um particular destaque conferido às relações concretas, às histórias de vida, aos compromisso para com os indivíduos singulares, aos afectos, aos contextos, considerando-os possuidores de virtualidades éticas. A consciência moral é sempre encarada "em situação", inserida em redes relacionais que se iniciam imediatamente no nascimento e que se mantêm ao longo da vida, numa atitude de permanente cuidado com a pessoa do outro.

Etty Hillesum foi alheia à temática teórica dos feminismos bem como à luta dos mesmos pela ocupação de um lugar cimeiro na política, na filosofia e na teologia. No entanto, a sua vida foi norteada pelos afectos mais do que pela razão, pela compaixão mais do que pela justiça, pelas emoções mais do que pelas obrigações. Daí podermos dizer que, com ela, estamos perante à vivência prática de uma ética do cuidado.

\section{Etty Hillesum como cuidadora}

Durante anos Etty Hillesum manteve-se desconhecida do grande público. Os seus diários e cartas datam do início dos anos quarenta do século XX, mas só em 1981 e 1986 foram publicados na Holanda — os Diários em 1981 e as Cartas em 1986. Mais tarde seguem-se traduções em inglês e francês, em múltiplas edições. Entre nós as versões portuguesas aparecem em 2008 e 2009, na Assírio e Alvim. A descoberta tardia da sua obra explica-se por várias razões, entre as quais o desinteresse dos editores locais perante uma obra deste teor - o êxito do Diário de Anne Frank parecia-Ihes ter esgotado o tema

\footnotetext{
${ }^{1}$ De entre as várias correntes feministas o chamado Feminismo Cultural distingue-se por valorizar positivamente os aspectos diferenciadores da personalidade feminina, dando relevo ao que é considerado próprio das mulheres.
} 
dos judeus holandeses durante a ocupação nazi. Também pesou neste esquecimento a difícil classificação do texto dos Diários ettyanos, misto de crónicas, reflexões literárias, considerações éticas e filosóficas, arroubos místicos. Porque a autora não se dirigia concretamente ao Deus dos judeus nem ao dos cristãos, os seus primeiros leitores foram pouco sensíveis ao itinerário espiritual por ela percorrido. Mas à medida que o seu testemunho de vida se divulgou, o nome desta judia holandesa impôs-se progressivamente como uma das grandes figuras da espiritualidade contemporânea. De facto, no Diário e nas Cartas que na mesma época escreveu aos amigos, assistimos ao relato de uma caminhada para Deus, por parte de alguém que, de início, 0 desconhecia, mas que, paulatinamente, estabeleceu com Ele uma relação absolutamente original. Simultaneamente assistimos a uma abertura e a uma atenção aos outros, pois familiares, amigos e pessoas carentes ocupam um lugar central nas suas Cartas e nos seus Diários.

Etty começou a escrever o seu diário em obediência a uma sugestão de Julius Spier, um Judeu berlinense refugiado na Holanda. Dotado de um grande poder de sedução, Spier exercia psicologia e quirologia. Etty estabeleceu com ele uma relação profissional que progressivamente se foi transformando em relação amorosa. Em ordem a aprofundar o seu auto-conhecimento e, sobretudo, para melhor poder auxiliar Spier no tratamento dos seus pacientes, Etty deveria analisar-se, relatando os seus estados de espírito. Através da sua escrita familiarizamo-nos com o seu dia a dia e tomamos conhecimento dos seus problemas familiares, das suas dúvidas existenciais, dos seus receios. De início deparamos com uma Etty marcada pela insegurança, solidão, medo e também atracção erótica por vários parceiros. Progressivamente, vemos desenrolar-se aos nossos olhos a estrada que a conduziu às profundezas do seu ser.

Escrito sem intenções de publicação, o Diário foi deixado à guarda de uma amiga, quando Etty ficou prisioneira no campo de Westerbork. A leitura desta obra (bem como a das cartas) interpela-nos a vários níveis. Em primeiro lugar, pelo seu interesse histórico pois tem como cenário a ocupação alemã da Holanda na Segunda Guerra Mundial. Também podemos lê-la numa perspectiva psicológica que nos permite acompanhar os conflitos interiores e as angústias de uma jovem judia, na sua tentativa de sobrevivência em tempos 
sombrios. Tempos em que as pessoas se circunscreviam ao dia a dia, impedidas de conjugar os verbos no futuro. No plano ético é-nos testemunhada a vivência da virtude do cuidado, por parte de alguém que nas situações mais complicadas manteve uma atenção permanente ao sofrimento alheio, esquecendo-se de si própria e estabelecendo um diálogo vivo com os outros e com Deus. Porque, tal como escreve no Diário, a sua fé deu-lhe forças para ultrapassar as dificuldades e acreditar no futuro:

Esta tarde, na grande caminhada de volta para casa, quando as ralações [...] pareciam não ter fim, disse subitamente para com os meus botões: se realmente acreditas em Deus, como afirmas, então deves ser consequente e entregar-te completamente e ter confiança. Como resultado, não deves preocupar-te também com o dia de amanhã (HILLESUM, 2008, p. 264).

O Diário e as Cartas de Etty dão-nos notícia da época dramática em que viveu, partilhando connosco as suas inquietações, as suas dúvidas, os seus temores. Iniciado a 9 de Março de 1941, o Diário estende-se até Outubro de 1942, data em que deixa o campo de Westerbork, rumo a Auschwitz. Na sua primeira parte assistimos a um período de relativa despreocupação e quase somos levados a pensar que situações dramáticas, como a guerra que então se vivia, são um mero pano de fundo para os problemas pessoais. Etty tem consciência dessa distorção e dela se penitencia pois com todo o sofrimento que a rodeia acha vergonhoso conferir tanta importância a si mesma. Julius Spier é a figura dominante, constituindo-se como o pólo aglutinador das suas alterações de humor e das suas preocupações. Mas para além desta relação, minuciosamente relatada nos seus pontos fortes e fracos, Etty distribui-se por múltiplas tarefas, envolve-se no conhecimento de si própria, cultiva diferentes amizades, inquieta-se com os pais e com os irmãos. Nesta fase é já particularmente visível a sua atitude de cuidadora, sendo a família uma das suas grandes preocupações. Há constantes referências à mãe, fortemente perturbada, bem como aos irmãos, ambos geniais, mas com graves desequilíbrios psíquicos. Logo no começo do Diário somos confrontados com as dificuldades experimentadas por Etty relativamente aos seus familiares. É lhe particularmente difícil perceber a sua mãe, sobre a qual escreve "é uma pessoa que sabe exasperar os outros até à medula" (HILLESUM, 2008, p. 104). Para além do seu emprego como governante de uma casa - com todos os 
problemas de gestão da mesma, bem como das amizades e conflitos com os seus diferentes habitantes - Etty estuda direito, literatura, psicologia e psicoterapia.

Neste período percebemos o modo como a prática do cuidado é central. Etty é cuidadora quando aplica aos pacientes de Spier as práticas que aprendeu com o mestre, assegurando-lhes a estabilidade e o conforto por eles pretendidos. A sua atenção e o seu cuidado também se fazem sentir, de um modo quase obsessivo, na relação com Spier, cuja doença e morte nos são detalhadamente relatadas. É cuidadora dos seus inúmeros amigos, que a encaram como confidente sempre disponível. Finalmente, é cuidadora relativamente ao seu povo. Embora desligada da cultura judaica, Etty não foi imune às perseguições ocorridas durante a ocupação nazi, partilhando-as voluntariamente. Através dos seus relatos, assistimos à degradação progressiva da situação dos judeus holandeses que, de pessoas de pleno direito, se transformaram em Untermenschen (sub-humanos), sujeitos a toda a espécie de arbitrariedades. De facto, com a ascensão dos fascismos e do nazismo a força anulou o direito, as discordâncias foram silenciadas, a ética foi esquecida. Etty solidarizou-se com os perseguidos, cujo destino partilhou. A sorte trágica que recaiu sobre os judeus e que, por consequência também a afectou, foi para ela a ocasião definitiva de pôr à prova a sua vocação de cuidadora. A 15 de Julho de 1942 passa a integrar o Conselho Judaico. E a partir daí a sua relação com o sofrimento dos deportados do Campo de Westerbork torna-se mais próxima. Compromete-se a segui-los e a partilhar com eles o muito amor que sente dentro de si.

O trabalho desenvolvido por Etty enquanto colaboradora do Conselho Judaico é o tema central do volume das Cartas. Elas constituem um testemunho tocante do modo como conseguiu ajudar os que estavam na antecâmara para os campos de morte. De igual modo nos informam sobre os estados de espírito de Etty, sobre os seus temores e angústias. Através desta obra tomamos consciência da sua inabalável confiança em Deus. E por ela percebemos o significado de uma expressão recorrentemente usada por Etty, referindo-se à sua situação no campo como "O coração pensante das barracas". 


\section{As diferentes manifestações de uma ética do cuidado em Etty Hillesum}

$\mathrm{Na}$ vida e nos escritos de Etty constatamos a presença de diferentes dimensões de uma ética do cuidado, nomeadamente nas suas vertentes terapêutica, amorosa, ética e espiritual.

Comecemos pela terapia. No seu Diário, Etty dá-nos a conhecer os métodos clínicos de Spier, com os quais se familiariza, primeiro como paciente e depois como parceira e colaboradora. Aceitando a tese de que "corpo e alma são uma só coisa" (HILLESUM, 2008, p. 63). Etty começa por querer conhecerse a si mesma e centra-se nos seus pequenos padecimentos físicos e amorosos. Considera que é importante dar-se conta das suas motivações, dos seus anseios e das suas fraquezas. Obedecendo ao objectivo do seu mestre, tenta transportar para o coração aquilo que apenas existe na mente: "Não se pode controlar tudo pela inteligência, é preciso deixar as fontes do sentimento e da intuição brotarem um pouco" (HILLESUM, 2008, p. 116). É um processo moroso que exige auto-conhecimento e meditação. Neste exercício Etty aprende a aceitar-se tal como é, com as suas capacidades e os seus limites. $\mathrm{E}$ olha para si com severidade: ao analisar a sua situação considera-se privilegiada pois em 1942 continua livre quando a maior parte dos seus amigos estão deportados, ou presos ou em fuga. Por isso sente-se responsável e moralmente obrigada relativamente aos que fazem parte do seu círculo. Aprende a aceitar as circunstâncias difíceis em que vive e procura encontrar um sentido para a vida, bem como para o sofrimento da humanidade. A pretensão de se explicar visa também uma melhor compreensão dos outros, tentando melhorá-los e melhorar o mundo: “[... ] não acredito que possamos melhorar alguma coisa do mundo exterior sem nos melhorarmos primeiro a nós próprios" (HILLESUM, 2008, p. 170). Deste modo, as situações mais desagradáveis e constrangedoras são por ela examinadas à lupa, numa procura de objectividade e de possíveis soluções.

Nessa viagem às profundezas do seu eu, Etty quer tornar-se mais simples e despojar-se do acessório. O que não a leva a desprezar as pequenas alegrias do dia a dia - apreciar a beleza de uma jarra de flores, gozar da companhia dos amigos, gratificar-se com os poemas de Rilke, apaixonar-se. 
Tem consciência de que na situação de grande stress emocional em que vive, importa separar o essencial do acessório, circunscrevendo-se ao estritamente necessário para manter o equilíbrio. Por isso tenta obedecer ao seu ritmo interior e procura não embarcar em visões fantasiosas de si mesma. Devido às circunstâncias em que está inserida, Etty tem plena consciência da possível brevidade da sua vida: "De repente a morte entrou na minha vida, grande, simples e óbvia, quase em silêncio" (HILLESUM, 2008, p. 219).

O cuidado dos outros evolui ao longo do Diário. No início notamos uma preocupação natural por todos, relevando-se a especificidade de cada um. Etty responde à amizade que lhe demonstram, e procura solucionar problemas concretos decorrentes de um relacionamento comunitário, pois a casa em que vive alberga gente muito diferente. Os habitantes da sua comunidade inquietam-na e ela tenta estabelecer harmonia entre todos, por mais diferentes que sejam. O seu objectivo é percebê-los, sem os catalogar nem os julgar, aceitá-los como são e ao mesmo tempo manter uma capacidade de distanciamento que lhe permita tomar posições. A variedade e diversidade dos seus amigos por vezes é-lhe dolorosa, mas prefere-os à solidão. Por muito que se sinta atraída pela reclusão, considera que é sempre melhor conviver com as pessoas e com o mundo.

À medida em que se aperta o cerco sobre os judeus, Etty interroga-se sobre as suas forças, bem como sobre a sua capacidade de ajudar os que sofrem. Ao escrever, com grande lucidez, sobre a sua fraca resistência física, antevê que, no caso de ser deportada para um campo de trabalho, a sua vida será breve. E interroga-se sobre a sua real capacidade de ajuda:

Será que já cheguei realmente ao ponto em que é preciso dizer: espero poder ir para o campo de trabalho a fim de fazer algo pelas raparigas de dezasseis anos que também vão? A fim de poder dizer com antecedência aos pais que ficam: Não se preocupem, eu tomo conta das vossas filhas? (HILLESUM, 2008, p. 242).

Etty tenta ultrapassar as constantes ameaças que sobre ela recaem. A sua defesa é encontrar um espaço de silêncio e de meditação. Ela o faz, mesmo quando o seu tempo é ocupado com tarefas inócuas, porém urgentes como seja preencher relatórios, atender pedidos, arrumar as mochilas dos que vão partir. A leitura do seu amado Rilke consegue consolá-la nos momentos mais 
dramáticos. E a contemplação de uma flor continua a surpreendê-la, mesmo quando a encontra num terreno cheio de lama. Deste modo, ganha forças com os pequenos momentos em que lhe é possível gozar a beleza das coisas, fruindo delas como alimento para a vida que pretende preservar dentro de si. Assim se explica que, na iminência de ser internada no campo de Westerbork, compre um ramo de rosas, num gesto gratuito que no entanto lhe dá coragem (HILLESUM, 2008, p. 267).

As relações afectivas e mesmo amorosas estão presentes ao longo do Diário. Temos a relação com Han, o dono da casa; com os diferentes amigos e namorados; com Spier, esse personagem estranho e contraditório que indelevelmente a marcou mas que ela nunca conseguiu compreender nem totalmente aceitar: "Amo-o imenso e ao mesmo tempo estou repleta de oposição a ele" (HILLESUM, 2008, p. 137). Não lhe basta uma só pessoa para que o seu desejo de amor se sinta realizado: "O meu coração é muito bravio, mas nunca por uma só pessoa. Para todas as pessoas" (HILLESUM, 2008, p. 129). Etty transborda de amor. Nesse abraço aos outros, coloca-os no centro da sua atenção, e não esquece a Natureza. O campo, o rio, as flores, constituem para ela pequenas alegrias que constantemente lhe lembram a presença de Deus.

A partir de 15 de Julho de 1942 Etty vai trabalhar para o campo de Westerbork como membro do Conselho Judaico. Para os que com ela lidaram nesse contexto, foi uma presença luminosa, o conforto possível dado pela palavra e pelo abraço. "O coração pensante da barraca" como se auto-denominou.

Westerbork é um local de passagem onde os judeus holandeses esperam transferência para outros destinos, inevitavelmente piores. Muitos deles alimentam a esperança de serem esquecidos, o que dificilmente acontece pois a máquina germânica é implacável. Semanalmente vão-se processando os carregamentos para Auschwitz ou para outras direcções igualmente sinistras. Nelas se integram os diferentes habitantes do campo: judeus de prática ou de sangue, padres e monges católicos de origem hebraica, ricos e pobres, intelectuais e iletrados, crianças e velhos. E doentes, muitos doentes. As pessoas empilham-se nos vagons de carga, alguns em macas. Etty presencia o horror em toda a sua nudez. Procurando tornar-se aguerrida mas 
não endurecida, mantém a capacidade de se compadecer e de participar no drama do qual é protagonista. O seu desejo é conseguir descrevê-lo para mais tarde se poder reconciliar consigo mesma e com a humanidade. A carta de 24 de Agosto de 1943 foi editada clandestinamente e publicada pouco tempo depois de ter sido escrita. Nela constatamos o drama das partidas, os atropelos aos doentes, aos velhos e crianças; o horror das mães que querem esconder os filhos, que os entregam a outros, que fazem chantagem, que recorrem a todos os subterfúgios para os salvar.

A função de Etty é "ajudar” a população flutuante dos deportados sobre os quais pende a constante ameaça dos campos de morte. Ela é uma espécie de assistente social, que procura resolver (com pouquíssimos meios) os problemas dos outros. O trabalho que então realiza é feito com grande empenhamento, usando e abusando das suas poucas forças. A sua ligação ao Conselho Judaico, dá-lhe um estatuto ligeiramente diferente dos restantes prisioneiros, assegura-lhe algumas saídas e adia indefinidamente uma deportação anunciada. Westerbork é o último patamar da viagem ao fundo de si mesma. É também o lugar onde encontra serenidade, onde se pacifica interiormente, onde quase podemos dizer que se sente feliz. De Westerbork sente nostalgia quando vem a casa para curtos períodos de descanso.

Ao inferno da lama e da doença Etty opõe o apelo à bondade e à beleza da vida, ao valor intrínseco da mesma, à sua indestrutibilidade e capacidade de regeneração. Não tem ilusões sobre o destino que a todos espera. Mas aposta na felicidade do momento. Consciente de que só é humilhado quem aceita a humilhação, Etty desafia a mesquinhez e a crueldade das leis do campo, afirmando-se interiormente livre. Não deixa no entanto de escrever aos amigos, denunciando a terrível situação dos internados:

Há momentos, é certo, em que sentimos que não aguentamos mais. Mas acabamos sempre por aguentar. [...] A miséria neste lugar é realmente indescritível. As pessoas dos barracões grandes vivem como ratazanas no esgoto. Vêem-se muitas crianças a morrer (HILLESUM, 2008, p. 152).

Etty tenta ultrapassar o sofrimento, apelando para algo que o possa redimir. Cuidadora da presença de Deus em si, desenvolve uma espiritualidade própria, conseguindo ver Deus onde ele parece estar mais afastado. Aprende 
a rezar em sítios insólitos, a meditar, a contemplar e a deixar-se possuir pelo sagrado, mesmo quando se dedica a tarefas comezinhas. À semelhança de Pascal, dá importância à corporalidade como caminho para Deus. Fala muito em como lhe faz bem ajoelhar-se e conta episódios em que se forçou a fazê-lo, mesmo quando tinha como cenário uma casa de banho e, como genuflexório, um tapete áspero de fibra de coco. Ajoelha-se nas latrinas, nos corredores apinhados de gente, no chão imundo de Westerbork. Aprende que a relação com Deus é das coisa mais íntimas que podemos experimentar, "quase mais íntimas do que as de teor sexual" (HILLESUM, 2008, p. 137). A relação com Deus torna-se cada vez mais intensa, de tal modo que embora tenha consciência de que está "nas garras dos alemães" sente que irá ser protegida pelos braços de Deus. Aquilo que Etty começou por designar como "os braços nus da Vida" (HILLESUM, 2008, p.187), passa a pouco e pouco a ser chamado Deus. E afirma reiteradamente "Dentro de mim está Deus".

Aos terríveis sofrimentos que presenciou no campo de Westerbork contrapõe a plenitude, a harmonia consigo mesma e com a natureza, a paz que advém de um despojamento total. Somos tocados pela sua capacidade de cantar a liberdade e de manter acesa a esperança, numa situação que em todos os aspectos parecem negá-la. Impressiona-nos a confiança em Deus que encontra no mais fundo de si mesma, um Deus que não conseguimos situar em nenhuma religião, mas que corresponde ao que há de melhor e de mais profundo em todos nós. Daí o permanente desejo de reconciliação consigo própria e com os outros, bem como a celebração da vida em todas as suas formas.

Em meados de Junho de 1942 a situação dos judeus agrava-se e a vida no campo de Westerbork é cada vez mais difícil. Mas Etty continua a afirmar que a vida é bela e que se sente livre:

Sim, meu Deus, sou-te muito fiel, para o que der e vier, e não vou deixar-me ir abaixo e continuo a acreditar no sentido profundo desta vida e sei como devo continuar a viver. E isto vai parecer-te incompreensível, mas acho a vida tão bela e sinto-me tão feliz (HILLESUM, 2008, p. 264).

As ameaças exteriores aumentam e o terror cresce, mas Etty usa a oração como um muro de defesa que a torna inexpugnável. Esgotada a 
esperança de uma alteração das condições de vida, rodeada por pessoas que aos poucos vão desaparecendo, levadas para campos de trabalho, ela toma consciência de um Deus diferente, um Deus frágil que precisa de ajuda: "Se Deus não me ajudar, nesse caso hei-de eu ajudar Deus" (HILLESUM, 2008, p. 245) e "Vou ajudar-te Deus, a não me abandonares, apesar de eu não garantir nada com antecedência" (HILLESUM, 2008, p. 252). Para ela a criação está incompleta e os homens terão que colaborar com Deus para a completar. Ela cuida de Deus e considera que colabora com Ele:

Quanto às circunstâncias pareces não ter lá muita influência sobre elas, é evidente que fazem parte indissolúvel desta vida. Também não te chamo à responsabilidade por isso; tu é que podes mais tarde chamar-nos à responsabilidade (HILLESUM, 2008, p. 252).

Na Carta 60 Etty escreve: “Deus Meu, fizeste-me tão rica, deixa-me por favor partilhar generosamente essa riqueza" (p. 200). Apesar de estar ciente do seu destino, bem como do que irá suceder aos internados em Westerbork, ela continua a proclamar a sua fé em Deus e na beleza da vida: "Acho esta vida bela e cheia de sentido. De minuto a minuto" (HILLESUM, p. 211). As belezas naturais são suficientes para lhe dar ânimo. E quando denuncia as condições infra-humanas em que vivem os habitantes do Campo, imediatamente as contrasta com as belezas naturais que apesar de tudo persistem, enchendo-a de esperança:

[...] estou com os esfaimados, com os maltratados e os moribundos, todos os dias, mas também estou com o jasmim, e com aquele pedaço de céu para lá da minha janela; para tudo existe um lugar na vida. Para uma fé em Deus e para um fim miserável (HILLESUM, 2008, p. 214).

Etty situa Deus no coração de cada um. Ele é o amigo que constantemente nos interpela, a quem falamos, a quem tentamos ajudar, ajudando-nos a nós próprios e aos outros. Ajudamo-Lo quando somos sensíveis à beleza da sua Criação e nos congratulamos com ela, oferecendo-a. É o que Etty faz, ao escrever:

Não te trago somente as minhas lágrimas e pressentimentos temerosos, até te trago, nesta tempestuosa e parda manhã de domingo, jasmim perfumado. E hei de trazer-te todas as flores que encontre pelo caminho, meu Deus, e a sério que 
são muitas. Hás de ficar sinceramente tão bem instalado em minha casa quanto é possível. [...] Se estivesse encerrada numa cela acanhada e uma nuvem passasse ao longo da minha janela gradeada, então eu iria trazer-te essa nuvem, meu Deus, se pelo menos ainda tivesse forças para isso (HILLESUM, 2008, p. 253).

É um Deus providencial e misericordioso, que dá na medida do necessário mas que precisa dos homens para agir, pois aposta nessa acção como completando a sua própria. No mais profundo da solidão e do sofrimento Etty encontra o sentimento da vida. O horror do quotidiano em Westerbork não mata nela o desejo de actuar mas, realisticamente, percebe que há alturas em que não pode agir; contentando-se com ser e aceitar. Uma aceitação que lhe impede a revolta, Ihe cala a angústia e lhe restitui o sentido de plenitude. À medida que se aproxima o final esperado, pressentido e quase conhecido, há uma sensação de eternidade, uma comunhão redentora com o sofrimento de todos: "Hoje estou realmente muito cansada. [... ] No entanto estou grata por não me teres deixado ficar sossegada a esta secretária, mas teres-me colocado no meio do sofrimento e das ralações desta época" (HILLESUM, 2008, p. 265). É esta a espiritualidade de Etty, a rapariga que agradece a Deus a sua vocação de cuidadora.

\section{Referências}

BOFF, L. Saber Cuidar. Ética do humano-compaixão pela terra, Petrópolis, Vozes, 1999.

FERREIRA, M. L. Ribeiro, "Espinosa e Ethy Hillesum". In: Nos passos de Etty Hillesum. Notas Espirituais de uma Peregrinação a Westerbork. Lisboa: Capela do Rato, 2017. p. 107-133.

FERREIRA, M. L. R. "Spinoza and Ethy Hillesum: Two different views of God". In: The Ethics and Religious Philosophy of Ethy Hillesum, Proceedings of the Ethy Hillesum Conference at Ghent University, January 2014, ed. by Klaas Smelik, Meins G.G. Coetsier and Jurgjen Wieserma, Brill. Leiden: Boston, 2017. p. 147-157.

FERREIRA, M. L. R. “A powerless God. Etthy Hillesum and Dietrich Bonhoeffer”. In: The Lasting Significance of Ethics and Religious Philosophy of Ethy Hillesum, ed. by Klaas Smelik. Amsterdam: Amsterdam University Press, 2019. p. 325-340.

FRANCISCO. FRATELLI TUTTI. Carta Encíclica sobre a Fraternidade e a Amizade Social. Prior Velho: Paulinas, 2020. 
FRANCISCO. LAUDATO SI'. Carta Encíclica sobre o Cuidado da Casa Comum. Prior Velho: Paulinas, 2015.

HILLESUM, E. Uma Vida Interrompida: os Diários de Etty Hillesum 1941-4. Rio de Janeiro: Editora Record, 1981.

HILLESUM, E. Diário, 1941-1943. Trad. Maria Leonor Raven-Gomes. Lisboa: Assírio e Alvim, 2008.

HILLESUM, E. Cartas 1941-1943. Trad. Ana Leonor Duarte e Patrícia Couto. Lisboa: Assírio e Alvim, 2009.

HILLESUM, E. The Complete Works 1941-1943. In: SMELIK, K.; COETSIER, M. (ed.). Maastrich: Shaker Verlag, 2014. (vols. 1 e 2).

MENDONÇA, J. T.; CONDADO, F. Nos Passos de Etty Hillesum. Lisboa: Documenta, 2016.

MICHAELDAVIDE, F. Etty Hillesum. Humanidade Enraizada em Deus. Prior Velho: Paulinas, 2016.

SENNFELT, C. "Westerbork". In: AAVV, Nos passos de Etty Hillesum. Notas Espirituais de uma Peregrinação a Westerbork. Lisboa: Capela do Rato, 2017. p. 71-81.

TAVARES, G. M. Aprender a rezar na era da técnica. Lisboa: Caminho, 2007.

WOODHOUSE, P. Etty Hillesum uma vida transformada. Lisboa: Paulinas, 2009. 